\title{
ARCHITECTURAL DESIGN BASED ON ENVIRONMENTAL PSYCHOLOGY PERSPECTIVES
}

\author{
Parisa Akbari \\ Architectural Engineering, Graduate Student \\ Hassan Sattarisarbangholi \\ Architectural Engineering, Doctor Of Architecture, Associate, Isalmic Azad University \\ Tabriz Branch
}

\begin{abstract}
Are architects able to design buildings whose frameworks help to promote the creativity and reduce social and internal dissonance of people and try to increase its efficiency in the environment? Answering this question needs understanding of factors affecting the issue, including understanding of the concepts and approaches of work alongside the rest of the directions in architectural design. By short overview of the concepts and procedures of perspectives on environmental psychology and its link with the architectural design in this article, it has tried to introduce the basic and new knowledge which is as old as 3 decades with artificial and manmade environment. The present article also turned its attention to expressing valuable theories of Environmental Psychology that awareness of them can have special significance for environmental design. In this article discussions about importance of understanding these issues for the design and especially architecture are presented. In the end, this writing has dealt with the summary and the final goal of the issue, which is architecture design within the modern science framework of environmental psychology and approaches and ideas.
\end{abstract}

Keywords: environmental psychology, architecture, psychology approaches, perspectives of Environmental Psychology

\section{INTRODUCTION}

Man since its inception is busy exploring nature, which has always been unknown and mystery to him, and is seeking comfort and efficiency of existing environmental conditions to gain peace. Architects and designers pay special attention to psychological understanding and further exploration in human behavior and nature in the environment because these behaviors are closely related with the physical environment.

What separates Environmental Psychology from the other branches of psychology is examining the relation between behavior based on the human psyche and the physical environment. Thus, attention of designers to psychological investigating of designed spaces has created an inextricable link between environmental psychology and them. Environmental psychologists have committed themselves to the study of human behavior in his daily environment to be able to directly or indirectly investigate effects of physical environment on human behavior.

Incorrect patterns of behavior in design and architecture, in addition to being unable to maintain the needs of people can even destroy the environment, while to long-term survival, we depend on the norms of the environment. Awareness of the role of behavioral sciences in the design of artifact environment is an action to solve the problem during which, artifact environment and emissions have the least harm to society and in addition to playing a key role in providing behavioral norms can enhance the utilization and use of space. Beginning of architects' awareness to Environmental Psychology approach in architectural designs throughout history can be considered alongside with the starting of architectural 
promotion and education by university's style which its impact of architecture can be seen in many of the great works. Ironically, all the architects who have studied the principles of design have been able to gain valuable theoretical and practical achievements. Because the architecture of today have been manipulated with tools such as power and wealth and considering that most architectural projects have been planned to serve humans, without this respect to individual psychological needs, it can be said: promoting the environment without respect to psychological needs in today's world is Cultural, social and economic nonsense. As we have seen several times, artifact spaces were created which did not have much of a welcome due to lack of attention to mentioned issues or have been forgotten over time.

Since it is thought architectural design should be based on psychological needs to maintain its dynamics over time, in this article after introduction to key concepts and perspectives of environmental psychology, we attempt to find the key issues of architectural design in creating an artificial environment. The methods used for this study is based on library studies and studies referred to written records. This research method is descriptive and analytical. The resulting data has been obtained through written sources for the library.

\section{ARCHITECTURAL DESIGN}

If you want to semantically review the term at different cultures, different meanings would be achieved According to the table below. It can be concluded from tables that all words based on the beliefs of all scientists have the same meaning.

\section{DEFINITION OF THE TERM DESIGN}

Table 1 definition of the term design

\begin{tabular}{|l|l|l|l}
\hline Definition & Book & Author & Year \\
\hline $\begin{array}{l}1 \text {.Plan suppliers; draftsman. 2. (Painting) } \\
\text { painter. (Amid, 1390, p. 1215) }\end{array}$ & $\begin{array}{l}\text { Amid Persian dictionary } \\
\text { (Volume II Sin to end) }\end{array}$ & Hassan Amid & 1390 \\
\hline $\begin{array}{l}\text { Draw an accurate and complete plan with } \\
\text { details. Make. Building. (Dehkhoda, (design)) } \\
\text { (Encyclopedia of Iranian Architecture, 1388, } \\
\text { p. 173) }\end{array}$ & $\begin{array}{l}\text { Encyclopedia of Iranian } \\
\text { architecture in Persian } \\
\text { references }\end{array}$ & $\begin{array}{l}\text { Seyed Mohammad } \\
\text { Beheshti } \\
\text { Mehrdad Qayumi } \\
\text { Bidhendi }\end{array}$ & 1388 \\
\hline $\begin{array}{l}\text { What does the designer (Moin, 1386, p. 727) } \\
\text { something without the use of color. 2. The }\end{array}$ & Moin Persian encyclopedia & Mohammad Moin & 1386 \\
\hline $\begin{array}{l}\text { drawing complete and accurate map of } \\
\text { something along with the details. (Day } \\
\text { speech, 1383, p. 803) }\end{array}$ & dictionary of day speech & Hassan Anvari & 1383 \\
\hline
\end{tabular}

Resource of table (1) based on (Amid, 1390- Encyclopedia of Iranian architecture, 1388- Moin, 1386Day speech, 1383) by the author.

\section{DEFINITION OF THE TERM ARCHITECTURE}

Table 2 definition of the term architecture

\begin{tabular}{|l|l|l|l}
\hline Definition & Book & Author & ear \\
\hline $\begin{array}{l}\text { Expert and professor in the construction, builder of the } \\
\text { mansion, mansion creator. (Amid, 1390, p. 1713) }\end{array}$ & $\begin{array}{l}\text { Amid Persian } \\
\text { dictionary (Volume } \\
\text { II Sin to end) }\end{array}$ & $\begin{array}{l}\text { Hassan } \\
\text { Amid }\end{array}$ & 1390 \\
\hline Science and art of designing and constructing buildings, a & Encyclopedia of & Seyed & 1388 \\
\hline
\end{tabular}

Submit Date: 01.05.2016, Acceptance Date: 20.06.2016, DOI NO: 10.7456/1060JSE/049 


\begin{tabular}{|c|c|c|c|}
\hline $\begin{array}{l}\text { branch of engineering that is the subject of design and } \\
\text { construction, style and method of designing and building } \\
\text { practice and jobs of architect } 0 \text { speech (architecture)) } \\
\text { (Encyclopedia of Iranian architecture, 138.8, p. } 243 \text { ( }\end{array}$ & $\begin{array}{l}\text { Iranian } \begin{array}{r}\text { architecture } \\
\text { in } \\
\text { references }\end{array} \\
\end{array}$ & $\begin{array}{l}\text { Mohamma } \\
\text { d Beheshti } \\
\text { Mehrdad } \\
\text { Qayumi } \\
\text { Bidhendi }\end{array}$ & \\
\hline $\begin{array}{l}1 \text {.Building and productive designer. 2. Mansion creator, a } \\
\text { repairman. 3. Rank in Freemasonry. (Moin, 1386, p. 1070) }\end{array}$ & $\begin{array}{l}\text { Moin Persian } \\
\text { encyclopedia }\end{array}$ & $\begin{array}{l}\text { Mohamma } \\
\text { d Moin }\end{array}$ & 1386 \\
\hline $\begin{array}{l}\text {.Knowledge and art of designing and constructing } \\
\text { buildings. 2. One branch of engineering that is the subject } \\
\text { of design and constructing buildings. 3. Designing and } \\
\text { building styles and methods. 4. Practice and architect's } \\
\text { job. (Day speech, } 1383, \text { p. } 1165 \text { ) }\end{array}$ & $\begin{array}{l}\text { dictionary of day } \\
\text { speech }\end{array}$ & $\begin{array}{l}\text { Hassan } \\
\text { Anvari }\end{array}$ & 1383 \\
\hline $\begin{array}{l}\text { g space } \\
\text { 2.principles of architecture is creating an atmosphere that } \\
\text { protects humans from harmful effects of natural factors } \\
\text { and includes the activities of his personal and social life } \\
\text { and meets his physical and spiritual needs. (Nikbakht, } \\
\text { Seyed al-Sadr, 1381, p. 544) }\end{array}$ & $\begin{array}{l}\text { Encyclopedia } \\
\text { architecture } \\
\text { urbanism }\end{array}$ & $\begin{array}{l}\text { Seyed } \\
\text { Sadr, } \\
\text { Seyed } \\
\text { Abolqasem }\end{array}$ & 1381 \\
\hline $\begin{array}{l}\text { Builder of mansion, creator of mansion, the expert and } \\
\text { professor at the construction work. (Omid, 1379, p. 933) }\end{array}$ & $\begin{array}{l}\text { Omid Persian } \\
\text { encyclopedia }\end{array}$ & $\begin{array}{l}\text { Mostafa } \\
\text { Rahiminia }\end{array}$ & 1379 \\
\hline
\end{tabular}

The source of table (2) based on (Amid, 1390-Encyclopedia of Iranian architecture, the 1388-Moin, 1386Day speech, 1383- Nikbakht, Seyed al-Sadr, 1381, pp. 544- Omid, 1379) from the author. Now if we want to understand the whole concept of architectural design, it can be said that architectural design is to create a building as a value conformity with the principles.

\section{ENVIRONMENTAL PSYCHOLOGY}

Environmental Psychology is the study of complex between people and their environment. According Gifford, environmental psychology is different from the main branch of psychology because focuses on daily physical environment. This science provides framework from the standpoint of ideas researches and assumptions which can help us to better understand the interactions of humans and the environment. By using this knowledge you can evaluate before designing and construction, which is considered as the best tool for professional designers. If we know what in the past has shown better performance, we will be more prepared for the future to better design. By using the stated related theory, it can be seen that environment plays a key role in the formation of values and empowerment of different individuals and groups. To realize this, we first discuss about getting familiar with expressed theories and concepts and influential factors in this regard.

Perspectives regarding environmental psychology:

\section{EXTERNAL PERSPECTIVES OF ENVIRONMENTAL PSYCHOLOGY}

Table 3 external perspectives of environmental psychology

\begin{tabular}{|l|l|l}
\hline \multicolumn{2}{|l|}{ author:MERYEM YALCIN,DR } & year:2015 \\
\hline resource: $\underline{\text { www.sciencedirect.com }}$ & $\begin{array}{l}\text { Work title: ( Exploratory and descriptive aspects of environmental } \\
\text { psychology course within the interior design education.) }\end{array}$ \\
\hline
\end{tabular}


Environmental psychology provides analytical point of view about existing built environment With a rich and diverse set of quantitative indicators to specify distances in many ways which are associated to A variety of psychological reactions, including the choice of routes while transfers, orientation and disorientation, the acquisition of knowledge space, perceived spaciousness, privacy and social interaction, stress, and fear, and aesthetic judgments (Kolb, 1984). Experiential learning theory is defined learning as "the process whereby knowledge is created through the transformation of experience". This study emphasize the "exploratory" and aspect of "descriptive" of environmental psychology in the context of real life, providing comprehensive information to and exported in a manner of complementary education in interior design.

The source of table (3) on the basis of information processing by the author.

Table 4: Foreign environmental psychology views

\begin{tabular}{|c|l|l|l}
\hline \multicolumn{3}{|c}{ Author:AYSEGUL DENIZ,BERRIN AKMAN } & Year :2012 \\
\hline \multicolumn{3}{|c|}{ Source:www.sciencedirect.com } & $\begin{array}{l}\text { Title of opus:( The Physical Environment Factors in } \\
\text { Preschools in Terms of Environmental Psychology) }\end{array}$ \\
\hline $\begin{array}{c}\text { Important } \\
\text { concepts of } \\
\text { opus }\end{array}$ & $\begin{array}{l}\text { This article is all explains about the importance of environmental psychology to } \\
\text { kindergarten. Field of environmental psychology has emphasized how the physical } \\
\text { environment affects the behavior and feelings. Kindergarten system where in the } \\
\text { environment is just one of many educational interaction, cultural and social factors, } \\
\text { programs, motivational and social and economic. Effective learning settings is a } \\
\text { combination of several different factors which can be used in space, noise, air } \\
\text { condition, color and brightness. }\end{array}$ \\
\hline
\end{tabular}

The source table (4) on the basis of information processing by the author.

\section{IRANIAN VIEWS OF ENVIRONMENTAL PSYCHOLOGY:}

Table 5: Iranian views of environmental psychology:

\begin{tabular}{|l|l|l}
\hline \multicolumn{2}{|l}{ Author: Nasser movahedi } & Year: 1391 \\
\hline $\begin{array}{l}\text { Source: } \\
\text { www.civilica.com }\end{array}$ & $\begin{array}{l}\text { Title of opus: Study on the role of environmental psychology in creating the } \\
\text { interest and enthusiasm in the visitors to shopping malls } \\
\text { Case of study: Laleh Park Mall in Tabriz }\end{array}$ \\
\hline \multirow{3}{*}{$\begin{array}{l}\text { Important concepts } \\
\text { of opus }\end{array}$} & $\begin{array}{l}\text { It seems that attentioning to the visual pleasure and psychological factors in } \\
\text { the design of these spaces can affect on social and economic dynamism and } \\
\text { increasing the social interactions significantly. Now, Designing of business } \\
\text { centers is experiencing major changes and new lines of thought influenced by } \\
\text { various sciences including environmental psychology are entered in design } \\
\text { and planning of commercial spaces. In this regard, the effect of spatial quality } \\
\text { of different aspects will be investigated in the uptake or utilization of space } \\
\text { visitors. Commercial spaces as economic and public spaces have included } \\
\text { multiple social, economic and physical functions, and have a key role to } \\
\text { realize the needs of today's life. According to psychological and } \\
\text { environmental factors ,it's effectived in designing the shopping malls in } \\
\text { attracting the attention and interesting of visitors and improving the position }\end{array}$ \\
\hline
\end{tabular}

Submit Date: 01.05.2016, Acceptance Date: 20.06.2016, DOI NO: 10.7456/1060JSE/049 
of these centers as architectural spaces with a lot of visitors.

The source table (5) based on the information processing by the author.

\section{THEORIES OF ENVIRONMENTAL PSYCHOLOGY}

Now that we are familiar with the term Environmental Psychology, we will examine the perspectives that are created in order to better understand this efficient issue. These theories are listed in the following graph which explanation of each are discussed in the following.

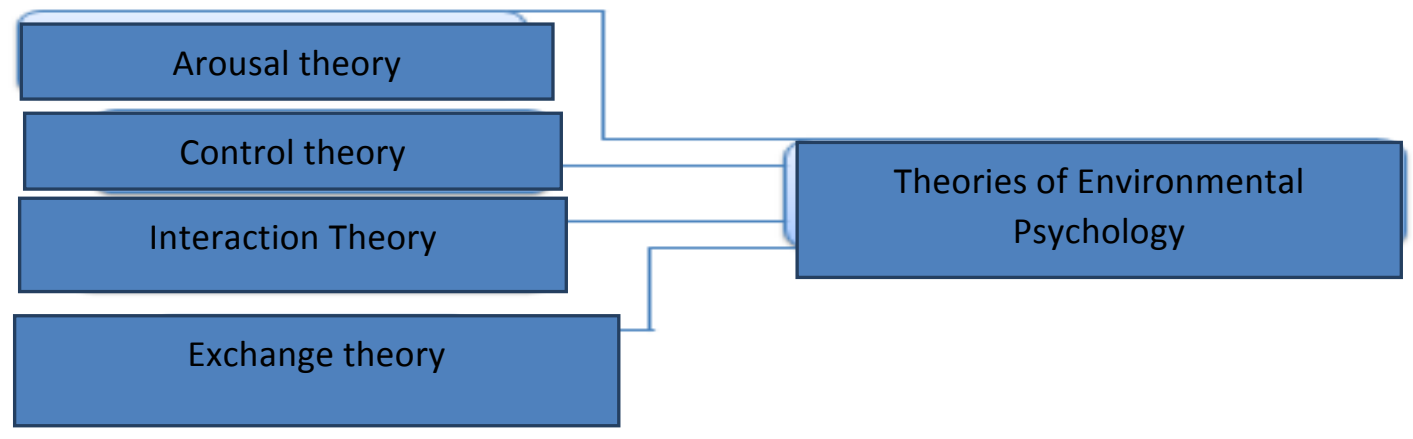

Figure 1 environmental theories of psychology

Source of Figure 1 Based on the author information processing

\section{AROUSAL THEORY}

In this perspective, Environment includes necessary conceptual information to maintain health, Such as different color and smell, heat, cold and more complex stimuli like buildings and landscapes, etc. One of the theories related to this theory is the theory of consistent level that determines the individual's need for environmental irritants amount is not fixed, but changes with the circumstances and the effect of sustainability. For example, people who live near noisy streets. Researches are done about this perspective. In some of these studies, severe stimulatory effect is examined and has made sustainability difficult and makes people feel more pressure. In others, the impact of extreme and unpleasant and monotonous or sudden, acute environmental irritants such as loud and sudden noises will be examined (Chabryt, 1991, quoted Shirin Rastgoo).

\section{CONTROL THEORY}

In this theory, the question is to what extent environmental stimuli can be controlled by humans or how much the power to control people should be. The ability to control environmental stimuli are present in the theory of personal control stated by Barner (1981). This theory and the theory of learned helplessness that Seligman (1975), it is expressed, shows such a situation arises when person is unsuccessful frequently and does not dominate and control the environmental conditions (Bondar and Kaul, 1978, quoted Shirin Rastgoo)

\section{INTERACTION THEORY}

The importance of this theory is due to the interaction of man and environment and compared with former theories is a kind of progress, in which the process was considered a one-dimensional phenomenon behavior. According to this perspective, the individual and the environment are constantly interacting and to understand the behavior, it is necessary to consider the environment and the individual as well as the interaction of these two (Kent Kirkik, 1971, quoted Shirin Rastgoo)

\section{EXCHANGE THEORY}

This theory is stated by Altman (1987). In this theory, the individual and the environment create a single set and no one alone can be defined. (Estokolz, 1990, quoted Shirin Rastgoo) Some psychologists 
including George Kelly theorize that every human individual has developed infrastructure for himself through which observe and interpret world events and in this way can predict and control events. He pointed out that "Languages of mind are in children structures, these structures make possible the waiting along with anticipation of change in events". Kelly notes that when personal structures fail in playing the role, a person feels threatened, guilt, hostility and aggression. Among the social learning theorists such as Julian Dotter (1954) believe that the potential behavior that occur in a particular situation is a function of expectation that one's have due to own behavior for the appropriate reward as well as the value of the reward for the person. (Vaziri, 1390, quoted Shirin Rastgoo)

\section{PROCESS OF RELATIONSHIP BETWEEN MAN AND ENVIRONMENT}

We humans are creatures not apart from surroundings and at any time we deal with it. But we should note that the relationship between us and environment is not limited to physiological exchanges such as respiration, excretion of wastes and... As we interact physically with the environment, have also emotional and psychological relationship with it. At any moment, we impact from environment and the information we achieve of it and impact on it conversely. In other words, our surrounding environment is full of potential information (reality).

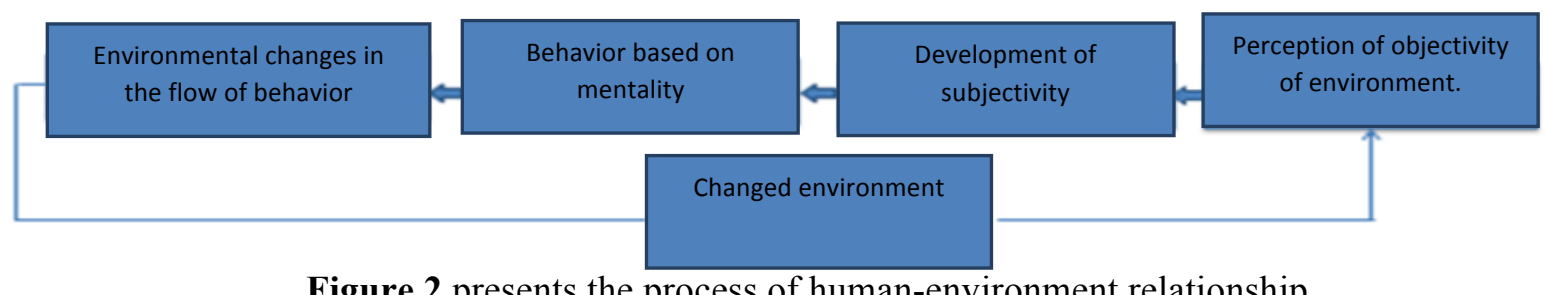

Figure 2 presents the process of human-environment relationship

Source of Figure 2 Pakzad, 1393, p. 45) on the basis of information processing by the author.

\section{CONCLUSION}

What was reviewed in the article is a review of environmental psychology perspectives and its role in creating an artificial environment by architectural design.

Due to limitations in the capacity to write this article, it is attempt in this paper to only application of a few index concepts and its approaches is briefly considered in environmental psychology. But the author acknowledges that it requires a wider range of available and acquired information through the development of this science and its application in architectural design.

Today, the design of the built environment in various forms is rely on their knowledge and awareness before rely on personal feelings and attitudes. Getting acquaint the designers with the knowledge that directly or indirectly helps design professional creates the opportunity for designers to plans provided by them be more consistent with the needs and culture of users and therefore environments designed by the architects provide necessary conditions to one or more human activity. Understanding other approaches and theories of environmental psychology alongside behavioral sciences can play an important role in this regard.

\section{REFERENCES}

Anvari, H., 1383, The day Culture of Discourse, Tehran, Sokhan.

Aizman, L., 1393, Applied Psychology of Colors (Pantone), Bayhaq Book Press, Fifth Edition.

Beheshti, M., Ghaiyoomi Bid Hendi, M., 1388, Dictionary of Iranian Architecture in Persian

Refrences, publisher of encyclopedia of architectural history of Iranshahr.

Pakzad, Dr. Jahanshah., 1393, Alphabet of Environmental Psychology for Designers, Armanshahr Press, second edition.

Pirnia, M. k., 1382, Stylistics of Iranian architecture, Soroush-e-Danesh press, Tehran.

Rahiminia, M., 1378, Omid Persian Encyclopedia, Fouad Press. 
Sultan Zadeh, H., 1386, From the Hall to Malls and Shopping centers, magazine of architecture and culture, No. 30, the ninth year.

Salimi Gargari, R., 1389, Basics of designing commercial spaces, Research Institute of future management of Arta plan.

Rastgoo, Sh.

Seyed Sadr, S., and Nikbakht, M., 1381, "Encyclopedia of Illustrated Architecture and Urbanism ", Azadeh Press, Tehran.

Amid, H., 1390, Amid Persian Encyclopedia, Publisher Ashjae.

Kiani, Mohammad Y., 1374, History of Iranian architecture Art in the Islamic period, Samt Press, Tehran. Memarian, GH. 1382, Introduction to Islamic Architecture, University of Science and Technology Press, Tehran.

Moeen, M., 1386, Moeen Persian Encyclopedia, Moeen Press.

DAN-CRISTIAN DABIJA, 2014, Measuring Clients' Satisfaction toward Shopping Centers - Empirical Evidences from Romania.

MERYEM YALCIN,DR, 2015, Exploratory and descriptive aspects of environmental psychology course within the interior design education.

AYSEGUL DENIZ,BERRIN AKMAN, 2012, The Physical Environment Factors in Preschools in Terms of Environmental Psychology.

www.sciencedirect.com

www.civilica.com

www.nabzezendegi.ir

www.bargozideha.com

www.bazarkhabar

daneshgahnews.com.www

forum.parsiking.com

www.fouman.com

www.niksalehi.com

www.tasnimnews.com 